Article

\title{
Beta-Cyclodextrin-Decorated Magnetic Activated Carbon as a Sorbent for Extraction and Enrichment of Steroid Hormones (Estrone, $\beta$-Estradiol, Hydrocortisone and Progesterone) for Liquid Chromatographic Analysis
}

\author{
Anele Mpupa ${ }^{1,2} \mathbb{D}$, Azile Nqombolo ${ }^{1,2}$, Boris Mizaikoff ${ }^{1,3} \mathbb{D}$ and Philiswa Nosizo Nomngongo ${ }^{1,2, *(\mathbb{D})}$ \\ 1 Department of Chemical Sciences, Doornfontein Campus, University of Johannesburg, P.O. Box 17011, \\ Johannesburg 2028, South Africa; ampupa@uj.ac.za (A.M.); azilen@uj.ac.za (A.N.); \\ boris.mizaikoff@uni-ulm.de (B.M.) \\ 2 Department of Science and Innovation-National Research Foundation South African Research Chair \\ Initiative (DSI-NRF SARChI), Nanotechnology for Water, University of Johannesburg, \\ Doornfontein 2028, South Africa \\ 3 Institute of Analytical and Bioanalytical Chemistry, Ulm University, Albert-Einstein-Allee 11, \\ 89081 Ulm, Germany \\ * Correspondence: pnnomngongo@uj.ac.za; Tel.: +27-11-559-6571
}

check for updates

Citation: Mpupa, A.; Nqombolo, A.; Mizaikoff, B.; Nomngongo, P.N. Beta-Cyclodextrin-Decorated Magnetic Activated Carbon as a Sorbent for Extraction and Enrichment of Steroid Hormones (Estrone, $\beta$-Estradiol, Hydrocortisone and Progesterone) for Liquid Chromatographic Analysis. Molecules 2022, 27, 248. https:// doi.org/10.3390/molecules27010248 Academic Editor: Tomasz Tuzimski

Received: 24 November 2021 Accepted: 28 December 2021 Published: 31 December 2021

Publisher's Note: MDPI stays neutral with regard to jurisdictional claims in published maps and institutional affiliations.

Copyright: (C) 2021 by the authors. Licensee MDPI, Basel, Switzerland. This article is an open access article distributed under the terms and conditions of the Creative Commons Attribution (CC BY) license (https:// creativecommons.org/licenses/by/ $4.0 /)$.

\begin{abstract}
A $\beta$-cyclodextrin-decorated magnetic activated carbon adsorbent was prepared and characterized using various analytical techniques (X-ray diffraction (XRD), scanning electron microscopyelectron diffraction spectroscopy (SEM-EDS) and transmission electron microscopy (TEM)), and the adsorbent was used in the development of a magnetic solid-phase microextraction (MSPE) method for the preconcentration of estrone, $\beta$-estradiol, hydrocortisone and progesterone in wastewater and river water samples. This method was optimized using the central composite design in order to determine the experimental parameters affecting the extraction procedure. The quantification of hormones was achieved using high-performance liquid chromatography equipped with a photodiode array detector (HPLC-DAD). Under optimum conditions, the linearity ranged from 0.04 to $300 \mu \mathrm{g} \mathrm{L}^{-1}$ with a correlation of determinations of 0.9969-0.9991. The limits of detection and quantification were between $0.01-0.03$ and $0.033-0.1 \mu \mathrm{g} \mathrm{L}^{-1}$, with intraday and interday precisions at 1.1-3.4 and 3.2-4.2. The equilibrium data were best described by the Langmuir isotherm model, and high adsorption capacities (217-294 $\mathrm{mg} \mathrm{g}^{-1}$ ) were obtained. The developed procedure demonstrated high potential as an effective technique for use in wastewater samples without significant interferences, and the adsorbent could be reused up to eight times.
\end{abstract}

Keywords: magnetic solid phase extraction; progesterone; hydrocortisone; estrone; $\beta$-estradiol; wastewater

\section{Introduction}

Steroids occur naturally in microorganisms, animals and plants. They primarily contain three cyclohexanes, one pentagonal carbon ring attached to different functional groups and side chains [1]. The steroid hormones are all derivatives of cholesterol and are also lowmolecular-weight lipophilic compounds [2,3]. Hormones can be broadly classified as either natural or synthetic [3]. Furthermore, they are divided into different families, including mineralocorticoids, glucocorticoids, androgens, estrogens and progesterone [4]. Glucocorticoids have been used as anabolic growth promoters due to their metabolic properties [5]. Hydrocortisone is a corticosteroid belonging to the glucocorticoid family. These types of hormones have found use in human medicine because of their immunosuppressive and anti-inflammatory properties [6,7]. Hydrocortisone is naturally produced by the adrenal cortex as a stress exposure response [8]. Hydrocortisone also takes part in the metabolism of fat, protein and carbohydrates [8]. Estrogens, such as estrone (E1), 17- $\beta$-estradiol (E2) 
and estriol (E3), are steroid hormones that are responsible for the upkeep of the health of breast, skin, brain and reproductive tissues [9]. Physiologically, progesterone (PRO) works as an estrogen hormonal balancer and is involved in the menstrual cycle, pregnancy and embryogenesis [10]. However, high levels of these hormones can increase the risk of osteoporosis, have neurotoxic effects on the central nervous system [5], decrease reproductive performance and the rate of fertilization in fish [11] and have potential carcinogenic effects on humans [3]. They are also considered as an endocrine disruptor, which can cause adverse effects on wildlife and humans by interacting with the endocrine system [12].

In recent years, traces of some steroid hormones have been found in food; these can be traced back to the use of hormones as growth promoters of animals in both industry and farm animals because of their anabolic effects [13,14]. In addition, some steroids (such as progesterone) are used as human and veterinary pharmaceuticals, and as a result, both humans and animals have become sources of environmental pollution. This is of great concern, as the presence of these compounds in food and water negatively affects some organs and systems, such as the cardiovascular system, tissues and the nervous system [15]. Thus, the EU and other countries such as China prohibit the use of hormones because of their potential to be endocrine disruptors in both wildlife and humans [13,15]. While the use of hormones has been banned, they can at times be found in compound mixtures to escape surveillance, thus resulting in residues of such chemicals being found in the environment [16]. As a result, highly sensitive and selective analytical methods are required for the determination of these hormones.

The most common methods for the determination of hormones include chromatographic methods, such as gas chromatography (GC) and liquid chromatography (LC), combined with mass spectrometry detectors for example quadrupole [17]; orbitrap mass spectroscopy [3]; and electrospray ionization mass spectroscopy amongst others [15]. However, due to the complexity of sample matrices, sample preparation is necessary to determine trace hormone residues [16]. Therefore, different sample preparation techniques have been used for the extraction of hormones from various sample matrices. These include, but are not limited to, solid-phase extraction [18], liquid-liquid extraction and hollow fiber liquid-phase microextraction [19]. Solid-phase extraction is one of the commonly used sample preparation techniques [20]. Because of its advantages, such as ease of operation, high enrichment factors and various sorbent materials, SPE is an attractive sample preparation technique for analytical chemists [21].

Activated carbon (AC) is one of the most used materials for the removal and extraction of organic pollutants [22]. Powdered activated carbon can be made from a range of organic materials and is reported to have functional groups that can absorb organic compounds, well-defined porosity and high specific surface areas [23]. Generally, AC is light in weight such that separation from aqueous solutions is a challenge. Thus, for practical application, combining $\mathrm{AC}$ powder with magnetic nanoparticles provides simple and quick use and the reuse of AC [24]. Beta-cyclodextrin ( $\beta-C D)$ is a cyclic oligosaccharide with hydrophobic inner cavities that can form host-guest interactions with the aid of supramolecular interaction between $\beta-C D$ and the analyte of interest $[25,26]$. Due to their attractive features, such as unique cavity, cost effectiveness, non-toxicity, biodegradability and renewable properties, $\beta-C D$ has proven to be an exceptional adsorbent [27-30]. However, $\beta-C D$ is highly soluble in water. For this, researchers have resolved this challenge by incorporation into a composite $[27,28]$ or by crosslinking or immobilization [29].

In this study, the combination of magnetic activated carbon and $\beta-C D$ as an adsorbent for the solid-phase extraction of selected steroid hormones in water samples prior to highperformance liquid chromatography-diode array detector (HPLC-DAD) was reported for the first time. The incorporation of magnetic activated carbon and $\beta-C D$ solved the problems of water solubility of $\beta-C D$ and the difficulties of recovering activated carbon after use. In addition, the composite combined the benefits of the hydrophobic cavity of $\beta-C D$, the high specific surface area of activated carbon and the magnetic properties of magnetite nanoparticles. The HPLC technique was chosen as an analytical method of choice due to its 
ease of operation and because no derivation step is required prior to analysis [31]. However, at trace levels, the HPLC technique encounters limitations in the detection of some organic compounds. As a result, a modified yet simple version of SPE was introduced as a sample preparation technique, where SPE was primarily selected for its inclusive nature for the use of modified adsorbents to increase the selectivity of the method [32]. The adsorbent was characterized by X-ray diffraction, scanning electron microscopy and transmission electron microscopy. The parameters affecting the extraction and preconcentration of the steroid hormones were investigated using response surface methodology.

\section{Materials and Methods}

\subsection{Materials and Reagents}

Hydrocortisone (HYD), $\beta$-estradiol (E2), progesterone (PRO) and estrone (E1) were obtained from Sigma-Aldrich (St. Louis, MO, USA). The physical properties and chemical structure of the analytes are presented in Table S1. Sodium hydroxide, acetic acid (99.9\%), methanol (HPLC grade), ferrous sulphate, ferric (III) chloride and $\beta$-cyclodextrin were all purchased from Sigma-Aldrich. A $20 \mathrm{mg} \mathrm{L}^{-1}$ mixed hormone stock solution was prepared by dissolving an appropriate amount of the analyte in HPLC-grade methanol and was kept chilled at $2{ }^{\circ} \mathrm{C}$. Standard solutions were prepared daily by diluting the stock solution with ultra-pure water (Direct-Q ${ }^{\circledR} 3 \mathrm{UV}-\mathrm{R}$ purifier system, Millipore, Merck).

\subsection{Instrumentation}

All $\mathrm{pH}$ measurements were carried out using an OHAUS ST series pen $\mathrm{pH}$ meter. The adsorption studies were carried out using the Branson 5800 Ultrasonic Cleaner (Danbury, CT, USA). A scanning electron microscopy (SEM, TESCAN VEGA 3 XMU, LMH instrument, Tescan Company, Brno, Czech Republic) coupled with energy dispersive X-ray spectroscopy (EDS) was used to study the morphology and elemental composition of the adsorbent at an accelerating voltage of $20 \mathrm{kV}$. The transmission electron microscopic image was captured using transmission electron microscopy (TEM, JEM-2100, JEOL, Tokyo, Japan).

An Agilent high-performance liquid chromatography (HPLC) 1200 Infinity series, equipped with a photodiode array detector (Agilent Technologies, Waldbronn, Germany), was used for all analyses. The separation was carried out using an Agilent Zorbax Eclipse Plus C18 column $(3.5 \mu \mathrm{m} \times 150 \mathrm{~mm} \times 4.6 \mathrm{~mm})$ (Agilent, Newport, CA, USA) operated at an oven temperature of $25^{\circ} \mathrm{C}$. The chromatograms were recorded using a $1.00 \mathrm{~mL} \mathrm{~min} \mathrm{~m}^{-1}$ flow rate and solvent mixture of 55\% mobile phase A (water) and $45 \%$ mobile phase $\mathrm{B}$ (acetonitrile), and adsorption wavelengths of 230,260, 280 and $288 \mathrm{~nm}$ using an isocratic elution system were used.

\subsection{Collection of Samples}

Wastewater samples (influent and effluent) were collected from a nearby urban wastewater treatment plant (Gauteng, South Africa) between January 2018 and December 2019. The river water samples were obtained from a river that receives WWTP effluent water. During the study period, 50 influent and effluent samples, as well as 50 downstream river water samples, were collected using the grab sampling technique. All samples were collected using clean $200 \mathrm{~mL}$ glass bottles and kept at $2{ }^{\circ} \mathrm{C}$ until use.

\subsection{Preparation of $\beta$-Cyclodextrin-Decorated Magnetic Activated Carbon}

Iron solutions of $0.75 \mathrm{~mol} \mathrm{~L}^{-1} \mathrm{FeCl}_{3}$ and $0.5 \mathrm{~mol} \mathrm{~L}{ }^{-1} \mathrm{FeSO}_{4} .7 \mathrm{H}_{2} \mathrm{O}$ were prepared separately. The iron solutions were dissolved at a $\mathrm{Fe}^{3+} / \mathrm{Fe}^{2+}$ ratio of 2:1 and stirred for $5 \mathrm{~min}$. Then, $4 \mathrm{~g}$ of $\beta$-cyclodextrin and activated carbon from waste tires (already prepared by Dimpe and colleagues [33]) were mixed via vigorous stirring and heated at $70{ }^{\circ} \mathrm{C}$. Subsequently, $5 \mathrm{~mol} \mathrm{~L}{ }^{-1} \mathrm{NaOH}(50 \mathrm{~mL})$ was added to the above solution and heating continued at $70{ }^{\circ} \mathrm{C}$ for $30 \mathrm{~min}$. A magnet was used to remove the black precipitate that formed during the changing of the color of the mixture. The resulting magnetic material was washed repetitively with a mixture of ethanol and water $(50 \% \mathrm{v} / v)$ solution to eliminate 
impurities (unreacted materials). Finally, the obtained magnetic material was dried in an oven at $80{ }^{\circ} \mathrm{C}$ for $24 \mathrm{~h}$ before use.

\subsection{Ultrasound-Assisted Magnetic Solid-Phase Microextraction Procedure}

An appropriate amount of adsorbent $(4.3-55.7 \mathrm{mg})$ was measured accurately into a glass vial with a cap; $5 \mathrm{~mL}$ of the sample (with $\mathrm{pH}$ adjusted accordingly from 4-9) was then added into the adsorbent. Thereafter, the adsorbent was dispersed using ultrasound in an ultrasonic water bath for the specified amount of time (7-32 min). After the time had elapsed, the supernatant was discarded, with separation achieved with the aid of an external magnet. The analyte was then eluted using an accurate volume (313-1086 $\mu \mathrm{L})$ of HPLC-grade methanol before analysis.

\subsection{Optimization of Extraction Procedure}

A multivariate optimization approach was used for the optimization of the sample preparation procedure. The optimization strategy was based on a $2^{4-1}$ fractional factorial design and central composite design to determine the experimental parameters that are significant for the preconcentration of steroid hormones. Table 1 shows the summary of the experimental design conditions for the fractional factorial and central composite designs.

Table 1. Parameter and levels used in $2^{4-1}$ fractional factorial design and central composite design.

\begin{tabular}{|c|c|c|c|c|c|}
\hline Factors & $-\alpha$ & $\begin{array}{c}\text { Low Level } \\
(-1)\end{array}$ & $\begin{array}{c}\text { Central } \\
\text { Point (0) }\end{array}$ & $\begin{array}{l}\text { High Level } \\
(+1)\end{array}$ & $+\alpha$ \\
\hline Mass of adsorbent (MA) (mg) & & 10 & 30 & 50 & \\
\hline $\mathrm{pH}$ & & 4 & 6.5 & 9 & \\
\hline Extraction time (ET) (min) & & 10 & 20 & 30 & \\
\hline Eluent volume $(\mu \mathrm{L})$ & & 400 & 700 & 1000 & \\
\hline Central composite design & $-\alpha$ & & & & $+\alpha$ \\
\hline Mass of adsorbent (MA) (mg) & 4.25 & 10 & 30 & 50 & 55.74 \\
\hline Extraction time (ET) (min) & 7.12 & 10 & 20 & 30 & 32.87 \\
\hline Eluent volume $(\mu \mathrm{L})$ & 313.8 & 400 & 700 & 1000 & 1086 \\
\hline
\end{tabular}

\subsection{Adsorption and Reusability}

The adsorption experiments were carried out according to the method described by Mashile and colleagues [34]. Briefly, $15.9 \mathrm{mg}$ of adsorbent was weighed and transferred into nine sealable glass containers. Then, $5 \mathrm{~mL}$ of stock solutions with varying concentrations (namely, 1-10 $\mathrm{mg} \mathrm{L}^{-1}$ ) was then added into the adsorbent. Agitation of the solution by an ultrasonic water bath was performed for $20 \mathrm{~min}$; thereafter, the adsorbent and supernatant were separated with the aid of an external magnet. Analysis of the supernatant $(1 \mathrm{~mL})$ was then carried out using $1 \mathrm{~mL}$ of the HPLC-DAD. In addition, the reusability of the adsorbent was also investigated by appropriate modification of a method described by Nyaba and coworkers [35].

\subsection{Method Validation}

After the determination of the optimum conditions, the developed method was validated according to Hoga and colleagues [36]. Under optimum conditions, the analytical figures of merit of the described method were evaluated using the limits of detection and quantification $(\mathrm{LOD}$ and LOQ) using the expressions $\mathrm{LOD}=(3 \times \mathrm{Sd}) / \mathrm{s}$ and $\mathrm{LOQ}=(10 \times \mathrm{Sd}) / \mathrm{s}$, where $S d$ and $s$ are the standard deviation of 10 replicate measurements at the lowest calibration concentration and slope, respectively. The linear ranges (LRs), correlation coefficient (R2) and enrichment factor were also determined using prepared sample solutions in the range of $50-500 \mu \mathrm{g} \mathrm{L}^{-1}$. The precision of the method was also investigated in terms of repeatability and reproducibility using the intraday precision (repeatability) $(n=15)$ and interday precision (reproducibility, $n=7$ working days). Validation of the developed method was carried out using spiked real sample recoveries due to the absence of certified reference 
materials (CRM). Briefly, the water samples were spiked at two levels (1 and $\left.5 \mu \mathrm{g} \mathrm{L}{ }^{-1}\right)$. The developed method was then applied to the unspiked and spiked water samples.

\section{Results and Discussion}

\subsection{Characterization}

3.1.1. Scanning Electron Microscopy (SEM) and Energy Dispersive X-ray Spectroscopy (EDS)

A morphological analysis of the prepared composite was carried out using SEM. The obtained image is shown in Figure 1A, where small aggregates were observed as a result of the magnetic iron present [37]. Analysis of the material's elemental composition was performed using EDS, whereby the expected elements resulting from the composite components were observed in their respective peak emissions. The results for the analysis are presented in Figure 1B.
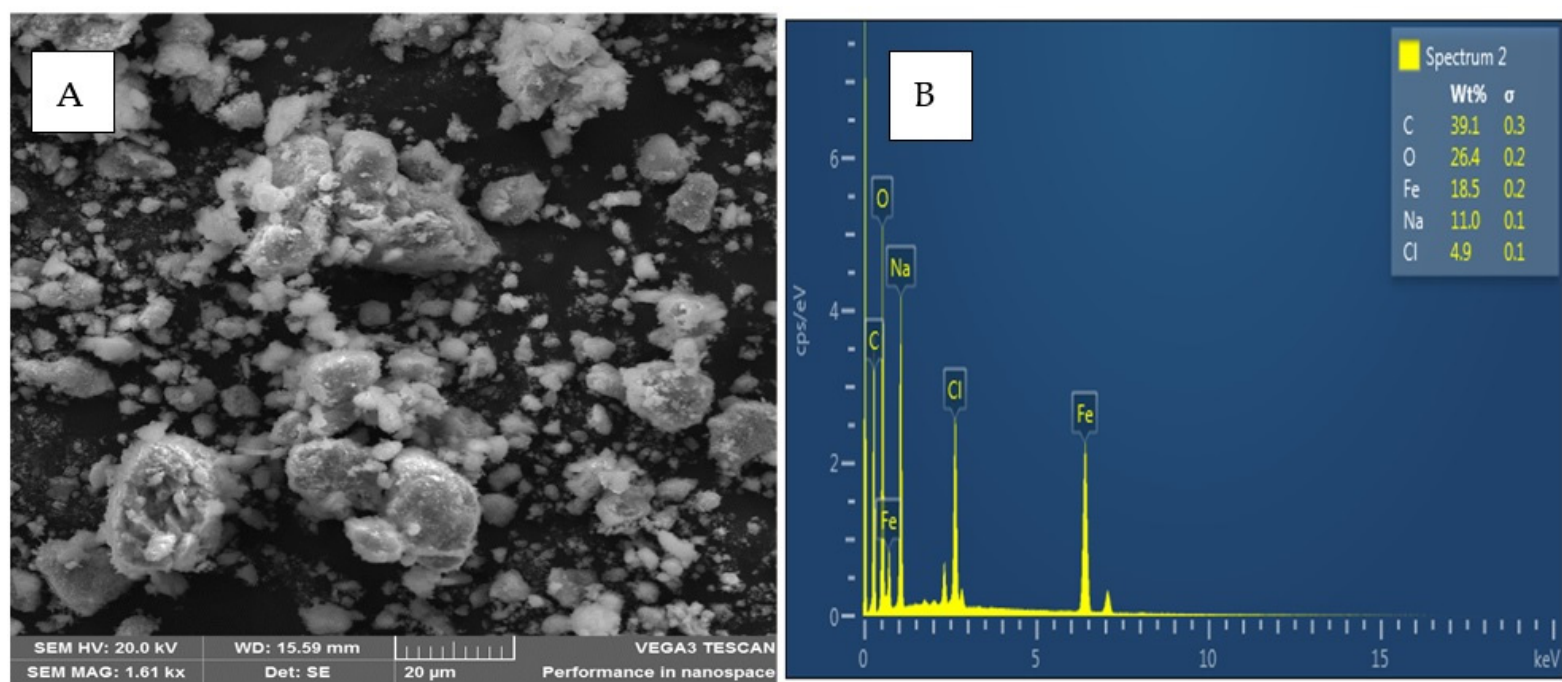

Figure 1. SEM image (A) and EDS microgram (B) for $\beta$-cyclodextrin-decorated magnetic activated carbon.

\subsubsection{Characterization of Adsorbent by Transmission Electron Microscopy}

Transmission electron microscopy (TEM) was used to study the in-depth structural views of the adsorbent material, and the captured images are presented in Figure 2. The resulting TEM images proved similar to those described by Filippou and coworkers [38], where the iron nanoparticles were attached on the activated carbon powder, which is seen on the image as the darker surface [37]. Similarly, with the SEM images, the material was aggregated as on the TEM capture. 


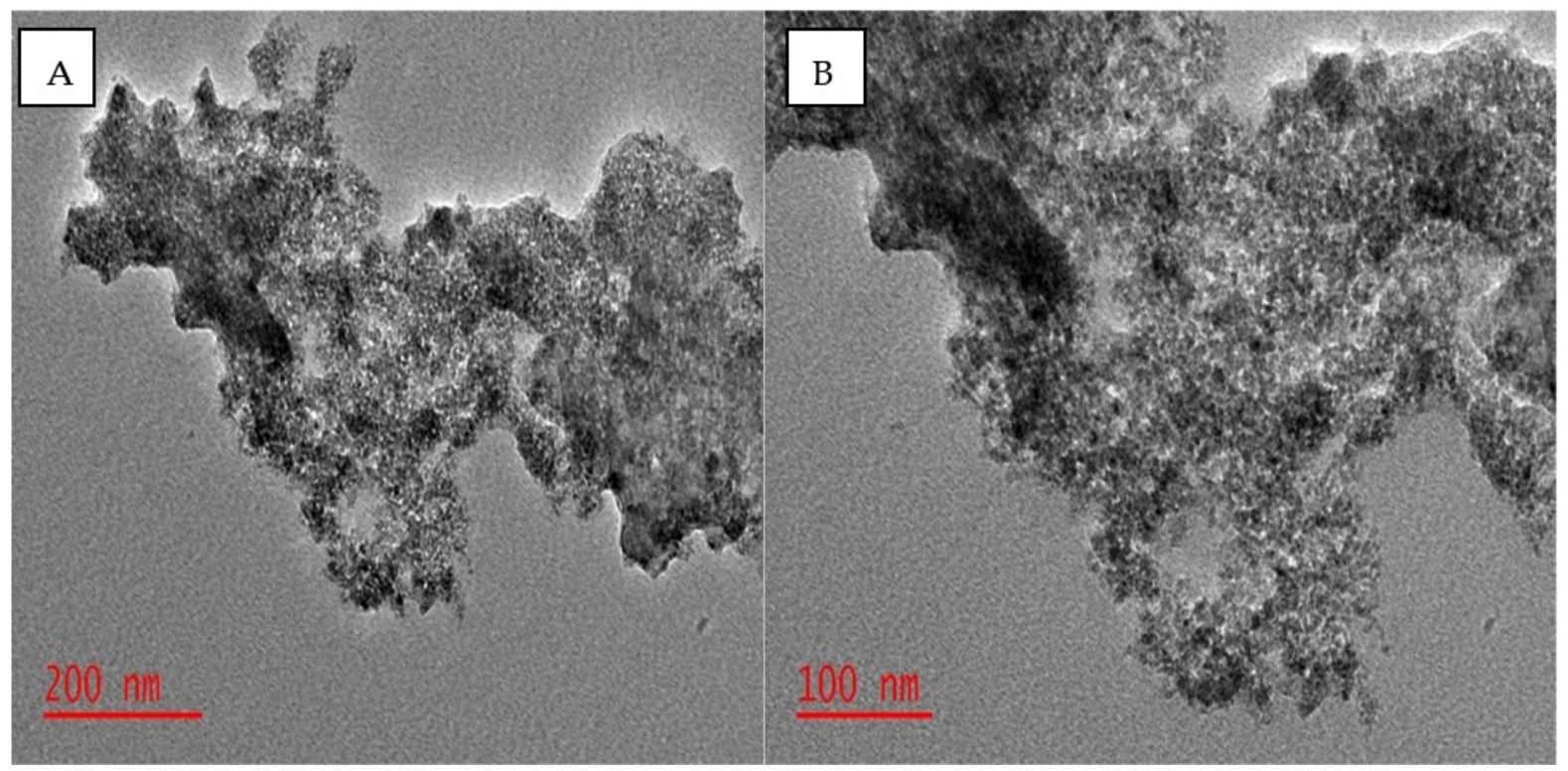

Figure 2. Transmission electron microscopy images of $\beta$-cyclodextrin magnetic activated carbon adsorbent at different magnifications: (A) $200 \mathrm{~nm}$ and (B) $100 \mathrm{~nm}$.

\subsubsection{X-ray Diffraction Spectroscopy}

To investigate the crystalline structure of the adsorbent, X-ray diffraction was used. Based on the reviewed literature, the expected diffraction peaks are those of the magnetic iron [38] and the activated carbon [33], while $\beta$-cyclodextrin did not have an effect on the XRD patterns [39]. The characteristic peaks for the cubic spinel crystal planes of magnetic iron were seen from $2 \theta=30.2(220), 35.56(311), 43.28$ (400, 57.6 (511) and 62.84 (440). The XRD patterns showed (Figure 3 ) the expected observations as described in the literature.

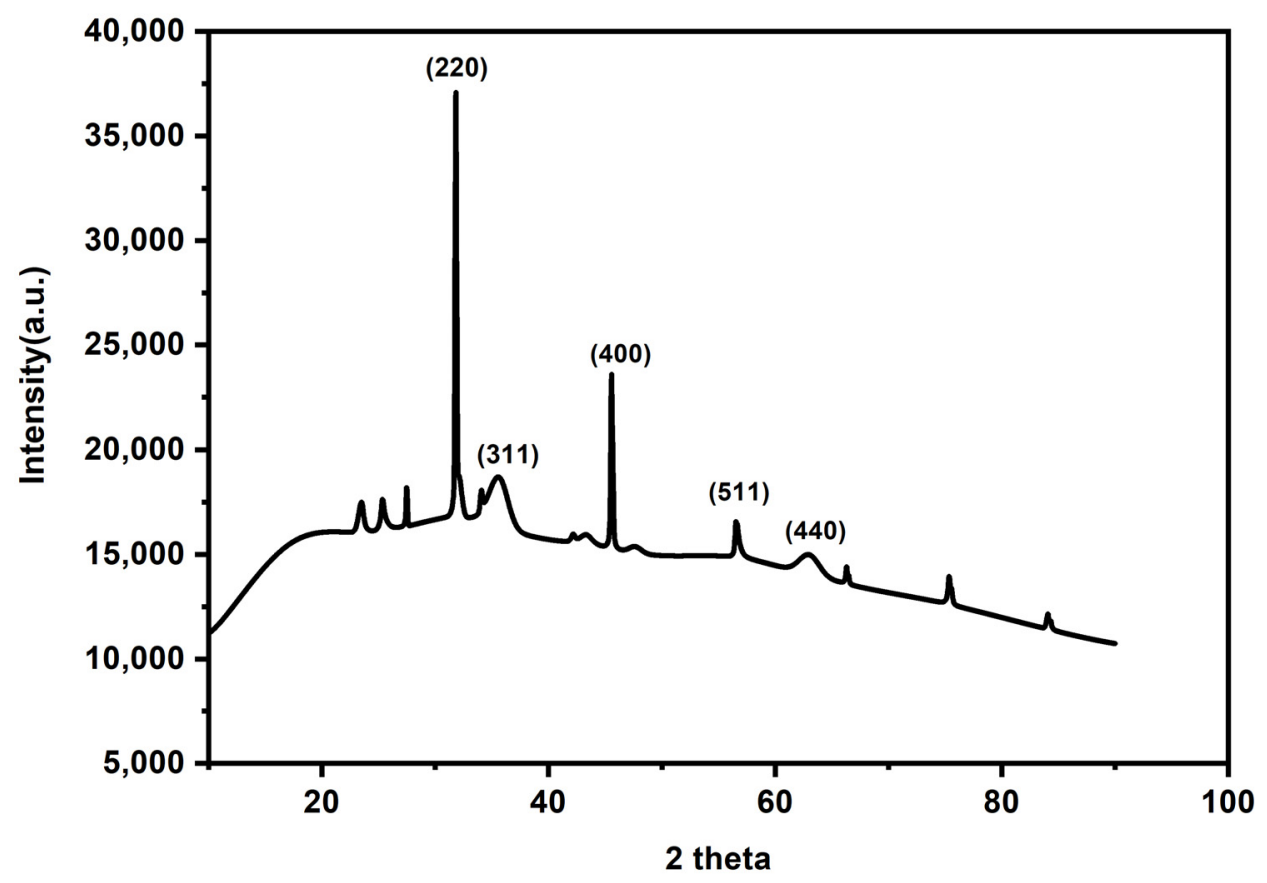

Figure 3. XRD diffraction pattern of the prepared adsorbent material. 


\subsection{Optimization of the MSPME Method}

\subsubsection{Selection of Adsorbent}

Considering that the activated carbon and cyclodextrin have large surface areas and inherent porous structure, their combination should be able to serve as an ideal adsorbent for the effective extraction of emerging pollutants. In this work, $\beta$-cyclodextrin-decorated magnetic activated carbon composite was prepared and used as an adsorbent for the preconcentration of steroid hormones. To investigate the adsorption capabilities of the composite, the performance of the adsorbent for the extraction of selected steroid hormones was compared with the activated carbon, magnetic nanoparticles, $\beta$-cyclodextrin and composite under the same conditions. The results shown in Figure 4 revealed that the composite displayed better adsorption capabilities compared to activated carbon, magnetic activated carbon and $\beta$-cyclodextrin. The improved adsorption capabilities of the composite for the selected hormones might be due to the combination of the attractive features of each component in the composite.

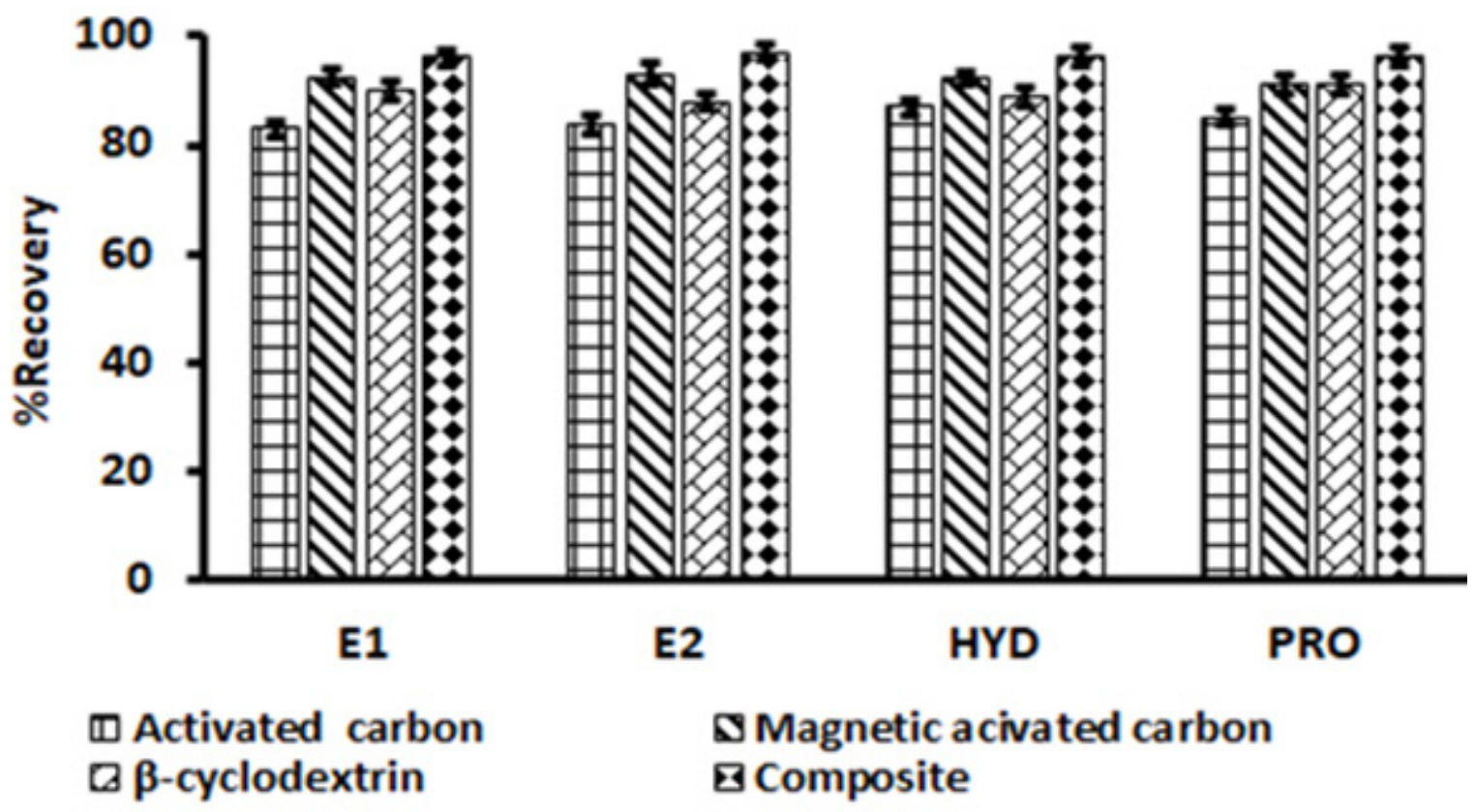

Figure 4. The adsorption performance of activated carbon, magnetic activated carbon, $\beta$-cyclodextrin and composite. Experimental conditions: mass of adsorbent $(20 \mathrm{mg})$, extraction time (30 min), eluent volume (1.0 mL), sample $\mathrm{pH}(6.5)$, elution time (10 min); sample $(5 \mathrm{~mL})$, eluent type (methanol), initial concentration $\left(200 \mu \mathrm{g} \mathrm{L}^{-1}\right)$.

\subsubsection{Screening Process Using Two-Level Fractional Factorial Design}

The most influential parameters were screened using a two-level fractional factorial design. In fractional factorial designs, the number of experiments is given by $2^{\mathrm{k}-\mathrm{p}}$, where $\mathrm{k}$ is the number of variables being studied and $\mathrm{p}$ is the indication of fractionation. FFD is used to check the preliminary significance of parameters of interest. This is achieved by estimating the main effects and their interactions while considerably reducing the number of conducted experiments [40]. These factors were the mass of the adsorbent; sample $\mathrm{pH}$; extraction time (ET), which was the time the samples were kept in the ultrasonic bath; and eluent volume $(\mathrm{EV})$.

The design matrix was analyzed with the aid of analysis of variance (ANOVA) to determine which factors and interactions had significance in the extraction of selected steroids. These results are presented in Figure 5 as Pareto charts. A factor is considered significant on a Pareto chart when the bar of that respective factor crosses the red line, which is considered as the $95 \%$ confidence level [41,42]. In this case, according to the obtained Pareto chart, the factors that affected the extraction of E1, E2 and PRO were MA, 
ET and EV and the interaction between $\mathrm{pH}$ and EV. The preconcentration of HYD, MA and $\mathrm{EV}$ and the interaction between $\mathrm{pH}$ and $\mathrm{EV}$ were significant at the $95 \%$ confidence level. The effect of $\mathrm{pH}$ was found to be significant for E1 but not significant for E2, HYD and PRO. This could be a result of the formation of an inclusion complex formed by $\beta$-cyclodextrin's interior cavity and the analyte in its molecular state $\left(\mathrm{pH}\right.$ lower than $\mathrm{pK}_{\mathrm{a}}, \mathrm{pK}_{\mathrm{a}}$ presented in Table S1) resulting in hydrogen bond interactions as well as $\pi-\pi$ interactions between the analyte and glucose monomers of $\beta$-cyclodextrin $[43,44]$. Thus, with further optimization, the central composite design (CCD) was used to optimize the effect of MA, ET and EV.
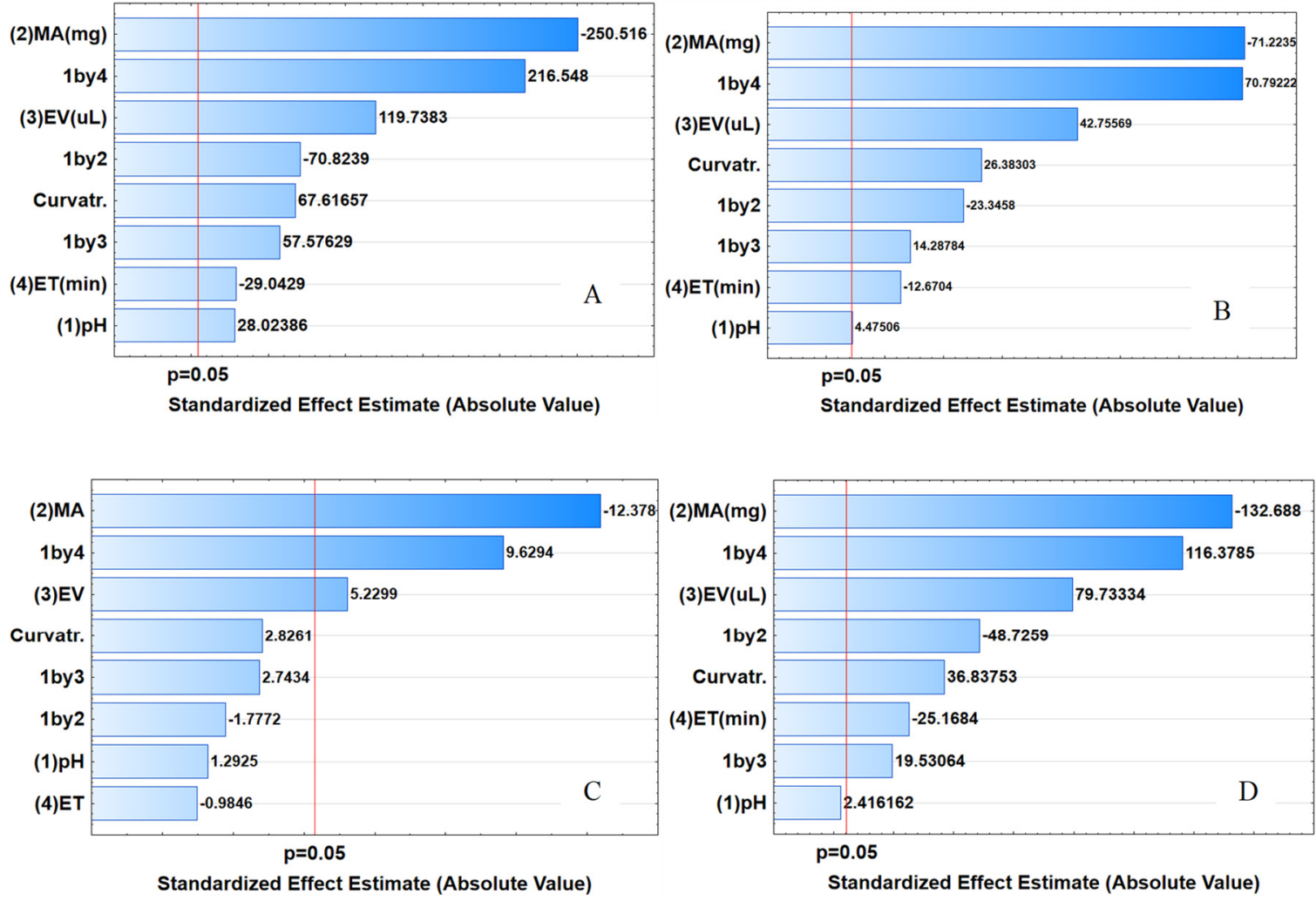

Figure 5. Pareto charts of standardized effects for variables in the preconcentration of steroid hormones (A) E1, (B) E2, (C) HYD and (D) PRO. (1) pH of working solution, (2) MA: mass of adsorbent, (3) EV: eluent volume, (4) ET: extraction time, 1by4: pH-ET interaction, 1by2: pH-MA interaction, 1by3: $\mathrm{pH}-\mathrm{EV}$ interaction.

\subsubsection{Response Surface Methodology and Desirability Function}

For further optimization of the significant factors, the central composite design method based on the surface response methodology (RSM) was used, where the three parameters (namely, MA, ET and EV) were optimized. Figure 6A,B show the combined effect of MA with ET and EV on the \% R. The results obtained indicate that better recoveries were obtained when the mass of adsorbent was greater than or equal to $10 \mathrm{mg}$. In addition, Figure 6A, C demonstrated that quantitative recoveries of target analytes were possible with an EV ranging from 400 to $1000 \mu \mathrm{L}$. The extraction time was found to be insignificant, suggesting that any time above zero could lead to quantitative recoveries. Finally, the interactions between ET and EV (Figure 6C), as well as ET and MA, show that EV and MA (Figure 6B) were the main contributors in the extraction and preconcentration of steroid hormones. The RSM plots for E2, HYD and PRO are presented in Figure S1. 

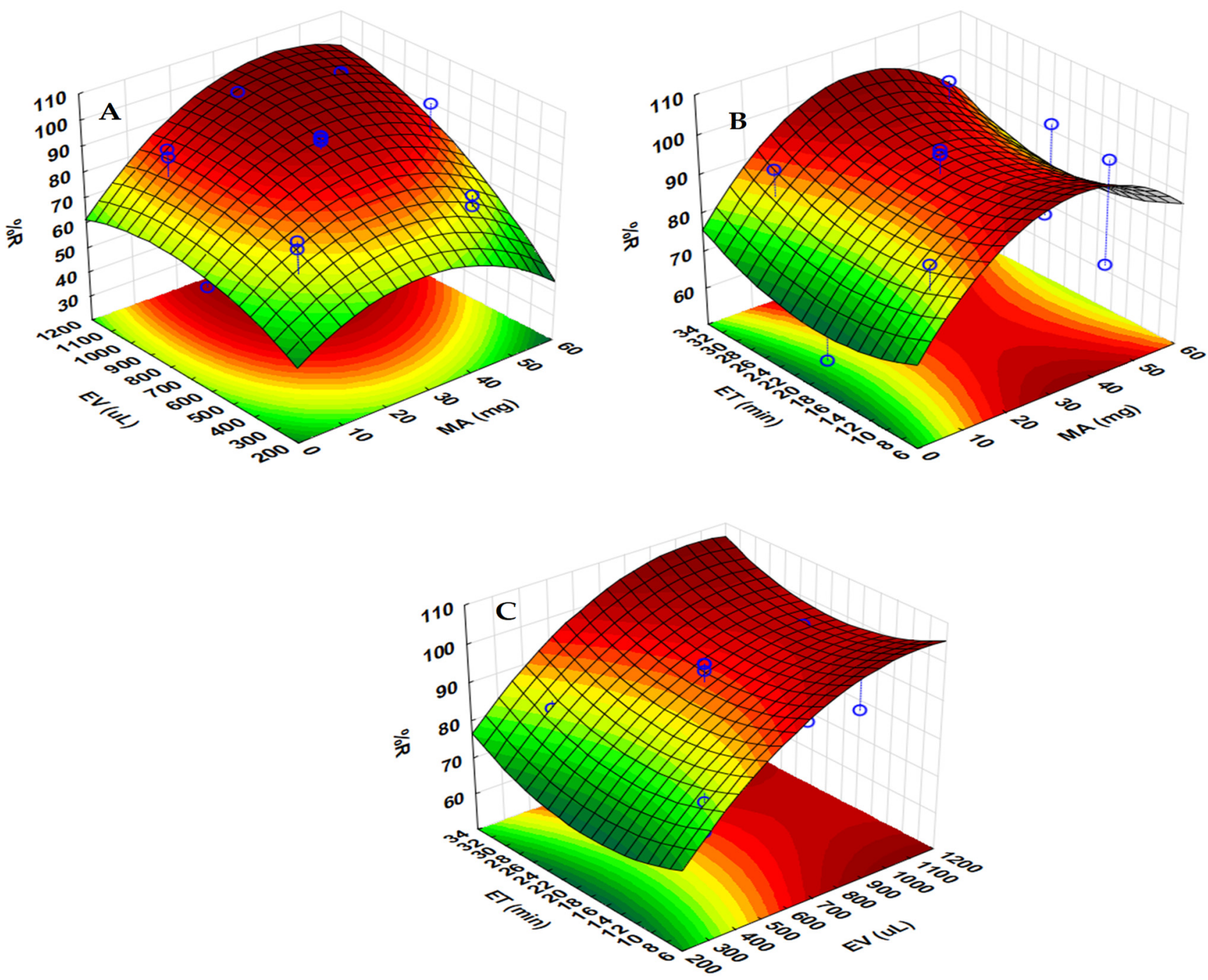

Figure 6. Three-dimensional response surface plot showing the result (E1) of the interaction of (A) eluent volume (EV) and mass of adsorbent (MA), (B) extraction time (ET) and MA and (C) EV and ET on \% R.

The 3D response surface plots shown in Figure 6, in addition to the profiles for desirability (Figure 7), were also used to determine the optimum conditions for the extraction procedure for E1 (desirability plots for E2, HYD and PRO are presented in Figure S2) Herein, a desirability score of 1.00 was assigned to a maximum recovery of $98.1 \%, 77.1 \%$ was assigned to a desirability of 0.5 , and a minimum $\% \mathrm{R}$ of $55.4 \%$ was associated with a desirability of 0 . A score of 1 for the factors was associated with the value required to achieve maximum extraction recovery [45]. The values for each factor were found to be $30 \mathrm{mg}$ for MA, $893 \mu \mathrm{L}$ for EV and $32 \mathrm{~min}$ for ET. Therefore, the overall optimum conditions used for the extraction procedure were a $\mathrm{pH}, \mathrm{MA}, \mathrm{ET}$ and $\mathrm{EV}$ of 7, $30 \mathrm{mg}, 32 \mathrm{~min}$ and $893 \mu \mathrm{L}$, respectively. The determined optimum conditions were validated experimentally, and the determined recovery was $99.3 \pm 0.4$, which agrees with the RSM model prediction at the $95 \%$ confidence level. 


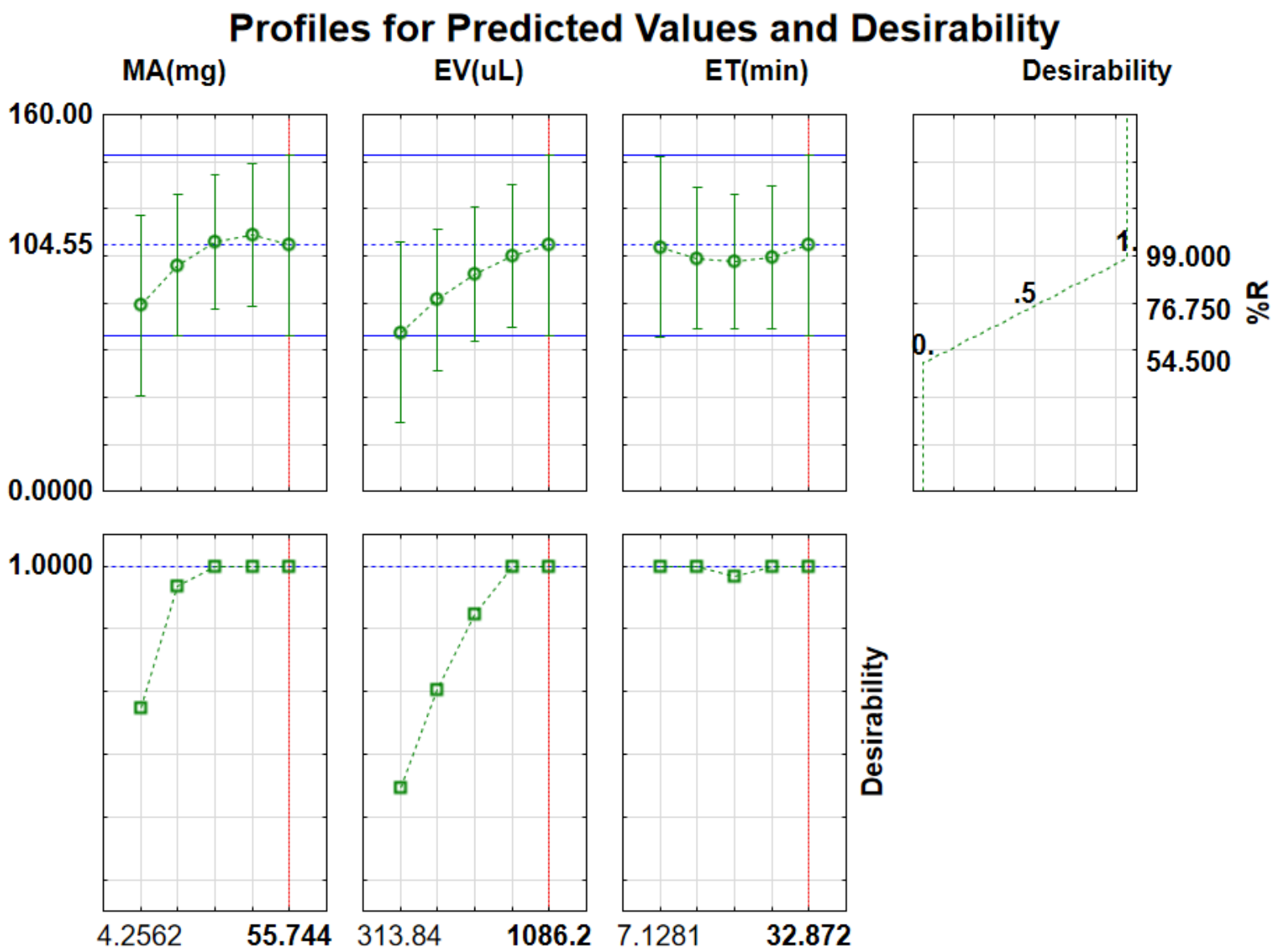

Figure 7. Profiles for desirability for the extraction of E1.

\subsubsection{Analytical Performance of MSPME-HPLC-DAD Method}

Under optimum conditions, the analytical figures of merit of the described method were evaluated using the limits of detection and quantification (LOD and LOQ). The linear ranges (LRs), correlation coefficient $\left(\mathrm{R}^{2}\right)$ and preconcentration factor were also determined using prepared sample solutions and are presented in Table 2. The method was found to be linear for the analytes in the range LOQ $-300 \mu \mathrm{g} \mathrm{L}^{-1}$ with correlation coefficients $\left(\mathrm{R}^{2}\right)$ 0.9988, 0.9991, 0.9969 and 0.9987 for E1, E2, HYD and PRO, respectively. The LODs for E1, E2, HYD and PRO were found to be $0.01,0.02,0.03$ and $0.02 \mu \mathrm{g} \mathrm{L}^{-1}$, while the LOQs for the same compounds were $0.033,0.067,0.1$ and $0.067 \mu \mathrm{g} \mathrm{L}^{-1}$, respectively. The method precision in terms of the interday and intraday was found to be 2.3, 2.5, 1.1 and 3.4 and 4.4, 3.5, 3.2 and 4.2 for E1, E2, HYD and PRO, respectively. The enrichment factors for the analytes were $93,81,90$ and 91 . The performance of the method was then further compared to other solid-phase methods reported in the literature in Table 3. The current method was found to have better LOD and precision compared to those reported by Liao and colleagues and Sampaio and coworkers [46,47]. Furthermore, the analytical performance was comparable to that reported by other researchers [48-50]. However, the LOD was higher than that reported elsewhere [6,51]. 
Table 2. Analytical performance of the developed preconcentration method.

\begin{tabular}{ccccc}
\hline Analytical Characteristics & E1 & E2 & HYD & PRO \\
\hline Linearity $\left(\mu \mathrm{g} \mathrm{L}^{-1}\right)$ & $0.04-250$ & $0.7-300$ & $0.1-250$ & $0.07-200$ \\
Correlation coefficient $\left(\mathrm{R}^{2}\right)$ & 0.9988 & 0.9991 & 0.9969 & 0.9987 \\
Limits of detection $(\mathrm{LOD})\left(\mu \mathrm{g} \mathrm{L}^{-1}\right)$ & 0.01 & 0.02 & 0.03 & 0.02 \\
Limits of quantification $(\mathrm{LOQ})\left(\mu \mathrm{g} \mathrm{L}^{-1}\right)$ & 0.033 & 0.067 & 0.10 & 0.067 \\
Enrichment factor & $93 \pm 2$ & $81 \pm 3$ & $90 \pm 2$ & $91 \pm 2$ \\
Recovery $(\%$, mean $\pm \mathrm{SD}, n=6)$ & 2.3 & $98.5 \pm 3.1$ & $9.9 \pm 2.1$ & 3.1 \\
Intraday precision $(n=10$ measurements), $\%$ & 4.4 & 3.5 & 3.2 & 4.2 \\
Interday precision $(n=5$ working days), $\%$ & & & & 4.1 \\
\hline
\end{tabular}

Table 3. Analytical performance comparison between current method and literature-reported methods.

\begin{tabular}{|c|c|c|c|c|c|}
\hline Analyte & Matrix & Analytical Technique & $\operatorname{LOD}\left(\mu \mathrm{g} \mathrm{L}^{-1}\right)$ & RSD & Reference \\
\hline Steroid hormones & Water samples & SPE-LC-APCI-MS/MS & $0.0058-0.015$ & $1-22$ & [48] \\
\hline $\mathrm{E} 2$ & Water and urine samples & SPME-HPLC & 0.12 & $<8$ & [46] \\
\hline E1, E2 & wastewater & SPE-GC-MS & $0.011-0.060$ & $0.10-0.28$ & [49] \\
\hline $\begin{array}{c}\text { Estradiol, } \\
\text { testosterone, PRO, } \\
\text { HYD }\end{array}$ & River water & ETA-SHS-ME-HPLC-UV & $0.002-0.0017$ & & {$[52]$} \\
\hline E1, E2 & Wastewater & SPE-HPLC-MS & $0.004-0.014$ & & [50] \\
\hline E1, E2 & Wastewater & RDSE-GC-MS & $0.003-0.006$ & $5-9$ & [51] \\
\hline E1, E2, PRO & Surface water & SPE-GC-MS & $0.13-0.3$ & $0.2-22$ & [47] \\
\hline E1, E2, PRO & $\begin{array}{c}\text { Wastewater and river } \\
\text { water }\end{array}$ & SPE-HPLC-MS/MS & $0.00002-0.0009$ & $<15$ & [6] \\
\hline E1, E2, HYD, PRO & $\begin{array}{c}\text { Wastewater and river } \\
\text { water }\end{array}$ & MSPME-HPLC-DAD & $0.01-0.03$ & $2.1-3.1$ & Current work \\
\hline
\end{tabular}

\subsubsection{Validation and Application}

Spike Recovery Test

In order to validate the proposed method, spiked influent wastewater samples and spiked recoveries were preferred due to the unavailability of certified reference material (CRM) for hormones. The results that are presented in Table 4 show that the proposed method showed good recoveries of $95-99.1 \%$ in influent, $93.5-102 \%$ in effluent and $96.6-$ $103 \%$ in river water.

Table 4. Validation parameters of the preconcentration method in water samples $(n=3)$.

\begin{tabular}{|c|c|c|c|c|c|c|c|}
\hline Analytes & & Influent & & Effluent & & River & \\
\hline \multirow{3}{*}{ E1 } & Added $\left(\mu \mathrm{g} \mathrm{L}^{-1}\right)$ & Found $\left(\mu \mathrm{g} \mathrm{L}^{-1}\right)$ & $\% \mathrm{R}$ & Found $\left(\mu \mathrm{g} \mathrm{L}^{-1}\right)$ & $\% \mathrm{R}$ & Found $\left(\mu \mathrm{g} \mathrm{L}^{-1}\right)$ & $\% \mathrm{R}$ \\
\hline & 0 & $0.120 \pm 0.005$ & & $0.0631 \pm 0.001$ & & $0.037 \pm 0.001$ & \\
\hline & 1 & $1.07 \pm 0.04$ & $95.2 \pm 3.7$ & $1.03 \pm 0.02$ & $97.1 \pm 1.9$ & $1.02 \pm 0.03$ & $98.2 \pm 2.9$ \\
\hline \multirow{3}{*}{ E2 } & 5 & $4.96 \pm 0.12$ & $96.7 \pm 2.4$ & $4.98 \pm 0.15$ & $98.3 \pm 1.2$ & $4.96 \pm 0.13$ & $98.5 \pm 2.6$ \\
\hline & 0 & $2.41 \pm 0.11$ & & $1.67 \pm 0.02$ & & $0.52 \pm 0.01$ & \\
\hline & 1 & $3.39 \pm 0.08$ & $97.8 \pm 2.4$ & $2.65 \pm 0.05$ & $98.3 \pm 1.9$ & $1.51 \pm 0.05$ & $98.5 \pm 3.3$ \\
\hline \multirow{3}{*}{ HYD } & 5 & $7.37 \pm 0.14$ & $99.1 \pm 1.9$ & $6.77 \pm 0.21$ & $102 \pm 3.1$ & $5.67 \pm 0.21$ & $103 \pm 3.7$ \\
\hline & 0 & ND & & ND & & ND & \\
\hline & 1 & $0.96 \pm 0.03$ & $95.6 \pm 3.1$ & $0.97 \pm 0.04$ & $96.7 \pm 4.1$ & $0.99 \pm 0.04$ & $98.5 \pm 4.1$ \\
\hline \multirow{4}{*}{ PRO } & 5 & $4.87 \pm 0.11$ & $97.3 \pm 2.6$ & $4.92 \pm 0.13$ & $98.4 \pm 2.6$ & $4.97 \pm 0.13$ & $99.3 \pm 2.6$ \\
\hline & 0 & ND & & ND & & ND & \\
\hline & 1 & $0.92 \pm 0.01$ & $92.3 \pm 1.1$ & $0.94 \pm 0.02$ & $93.5 \pm 2.1$ & $0.97 \pm 0.04$ & $96.6 \pm 4.1$ \\
\hline & 5 & $4.78 \pm 0.14$ & $95.5 \pm 2.9$ & $4.82 \pm 0.17$ & $96.3 \pm 3.5$ & $4.88 \pm 0.17$ & $97.6 \pm 3.5$ \\
\hline
\end{tabular}


Determination of Selected Steroid Hormones in Wastewater (Influent and Effluent) and River Samples

Based on the acceptable recovery test results, the developed analytical method was applied for the extraction and preconcentration of steroid hormones in influent, effluent and river water samples collected from an urban wastewater treatment and nearby river. The obtained results are summarized in Table 5. The results showed that E1, E2 and PRO were detected in wastewater influent and effluent, as well as river water samples, while HYD was only detected in wastewater samples. In the wastewater samples, the mean concentrations ranged from 32.3 to $35.9 \mathrm{ng} \mathrm{L}-1,1132$ to $2414 \mathrm{ng} \mathrm{L}^{-1}, 1.07$ to $2.50 \mathrm{ng} \mathrm{L}^{-1}$ and 3.92 to $6.35 \mathrm{ng} \mathrm{L}^{-1}$ for E1, E2, HYD and PRO, respectively. The presence of E1, E2 and $\mathrm{PRO}$ in the river water samples could be due to the incomplete removal of these hormones during the treatment process. The obtained results proved that combining a less sensitive chromatographic technique such as HPLC-DAD with MSPME (preconcentration method) could lead to an accurate quantification of E1, E2, HYD and PRO at the ultratrace level (nanograms per liter levels). A typical chromatogram for the determination of target analytes in real water samples is shown in Figure S3.

Table 5. Minimum (min), maximum (max) and mean concentration (ng $\mathrm{L}^{-1}$ ) of four steroid hormones in influent wastewater, effluent wastewater and river water samples: $n=$ number of samples containing detectable amounts of target analytes.

\begin{tabular}{cccccccccc}
\hline Analytes & \multicolumn{2}{c}{ Influent Wastewater $(\boldsymbol{n}=\mathbf{3 5})$} & \multicolumn{2}{c}{ Effluent Wastewater $(\boldsymbol{n}=\mathbf{3 5})$} & \multicolumn{3}{c}{ River Water $(\boldsymbol{n}=\mathbf{2 0})$} \\
\hline & Min & Max & Mean & Min & Max & Mean & Min & Max & Mean \\
E1 & 15.7 & 126 & 35.9 & 10.4 & 57.8 & 32.3 & 10.4 & 63.1 & 30.0 \\
E2 & 143 & 6234 & 2414 & 67.4 & 2207 & 1132 & 124 & 948 & 463 \\
HYD & LOO & 87.5 & 2.50 & $<$ LOQ & 37.3 & 1.07 & $<$ LOQ & $<$ LOQ & $<$ LOQ \\
PRO & LOOQ & 127 & 6.35 & <OQ & 78.3 & 3.92 & $<$ LOQ & 68.3 & 3.42 \\
\hline
\end{tabular}

The results obtained in this study were compared with those reported by other researchers. Mhuka and colleagues [53] reported E1, E2, PRO concentrations in South African influent (E1: < LOD-35.96 ng L ${ }^{-1}$; E2: 66.45-2206 ng L ${ }^{-1}$; PRO: LOD-14.5 $\mathrm{ng} \mathrm{L}^{-1}$ ), effluent (E1: < LOD-60.83 ng L ${ }^{-1}$; E2: 154.1-7133 $\mathrm{ng} \mathrm{L}^{-1}$; PRO: LOD-4.03 $\mathrm{ng} \mathrm{L}^{-1}$ ) and river water (E1: 7.12-63.04 $\mathrm{ng} \mathrm{L}^{-1}$; E2: 134.7-644 $\mathrm{ng} \mathrm{L}^{-1}$; PRO: LOD-2.20 $\mathrm{ng} \mathrm{L}^{-1}$ ). These values are comparable or higher than the results obtained in the current study. Merlo and colleagues [6] conducted a study on the determination of E1, E2 and PRO in river water and wastewater treatment plant (WWTP) effluent collected from high-density populated areas of northern Italy. Their concentrations (E1: 14-76 ng L ${ }^{-1}$; E2 < LOQ-34 ng L ${ }^{-1}$; PRO: 4-10 ng L ${ }^{-1}$ ) were lower than the ones obtained in this study. The concentrations of E1 and E2 in Chilean wastewater (influent and effluent) samples were found to be 15-16 and 0-48 ng L ${ }^{-1}$ [51]. Sampaio and colleagues [47] investigated E1, E2 and PRO at concentrations ranging from 1110 to $1580 \mathrm{ng} \mathrm{L}^{-1}$ in Brazilian surface water samples.

\subsubsection{Adsorption and Reusability}

Adsorption Studies

Equilibrium adsorption data for the proposed method were investigated using Langmuir [54] and Freundlich [55] models; linearized equations for each model were used and are shown in Equations (1) and (2), respectively:

$$
\frac{C_{e}}{q_{e}}=\frac{1}{q_{\max }} C_{e}+\frac{1}{K_{L} q_{\max }}
$$


where $q_{e}$ is the equilibrium adsorption capacity $\left(\mathrm{mg} \mathrm{g}^{-1}\right), q_{\max }$ is the maximum monolayer adsorption capacity $\left(\mathrm{mg} \mathrm{g}^{-1}\right), K_{L}$ is the Langmuir constant $\left(\mathrm{L} \mathrm{mg}^{-1}\right)$, and $C_{e}$ is the concentration of adsorbate at equilibrium $\left(\mathrm{mg} \mathrm{L}^{-1}\right)$.

$$
\ln q_{e}=\ln K_{F}+\frac{1}{n} \ln C_{e}
$$

where $K_{F}$ is the measure of adsorption capacity, $C_{e}$ is the concentration of adsorbate at equilibrium $\left(\mathrm{mg} \mathrm{L}^{-1}\right)$, and $n$ is an adsorption effectiveness indicator.

The plots of $C_{e} / q_{e}$ against $C_{e}$, and $\ln q_{e}$ versus $\ln C_{e}$, for the Langmuir and Freundlich models are presented in Figure 8. The correlation coefficients $\left(R^{2}\right)$ are presented in Table 6 and show that the $R^{2}$ values for the Langmuir models are higher than the Freundlich models. This implies that the adsorption of the steroid hormones took place at particular homogeneous sites and as a monolayer adsorption onto the surface of the magnetic adsorbent [56]. The values of $q_{\max }$ and $K_{L}$ were obtained from the intercept and slope of the plot (Figure 8), and they were found to be $217 \mathrm{mg} \mathrm{g}^{-1}$ and $9.2 \mathrm{~L} \mathrm{mg}^{-1}, 244 \mathrm{mg} \mathrm{g}^{-1}$ and 6.8 $\mathrm{L} \mathrm{mg}^{-1}, 270 \mathrm{mg} \mathrm{g}^{-1}$ and $6.2 \mathrm{~L} \mathrm{mg}^{-1}$ and $294 \mathrm{mg} \mathrm{g}^{-1}$ and $4.9 \mathrm{~L} \mathrm{mg}^{-1}$ for E1, E2, HYD and $\mathrm{PRO}$, respectively.
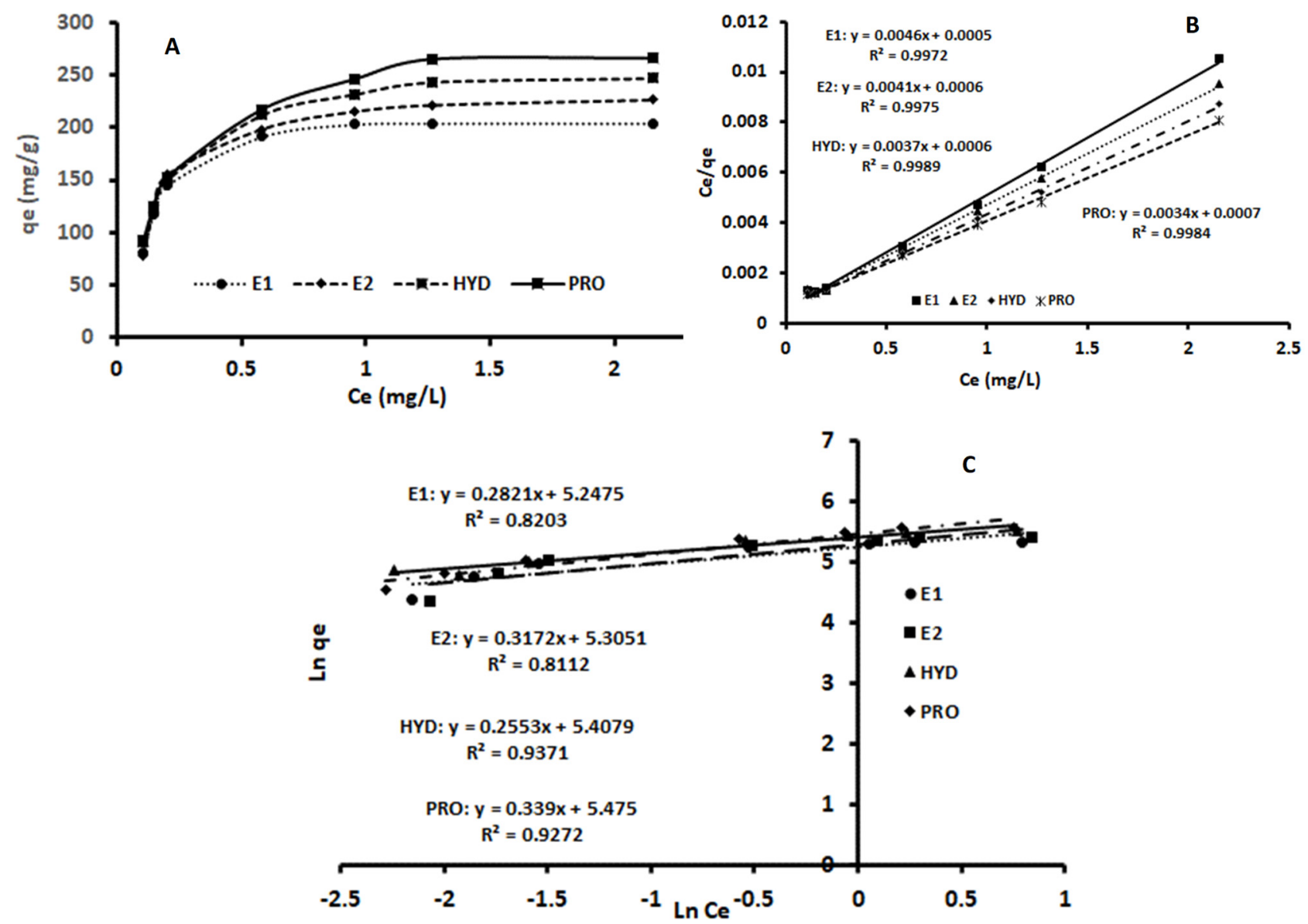

Figure 8. Plots of $C_{e} / q_{e}$ against $C_{e}$ (A), and $\ln q_{e}$ versus $\ln C_{e}$, for Langmuir (B) and Freundlich (C) models. 
Table 6. Langmuir and Freundlich adsorption models and parameters investigated in the study.

\begin{tabular}{cccccc}
\hline & Parameters & E1 & E2 & HYD & PRO \\
\hline \multirow{2}{*}{ Langmuir } & $q_{\max }\left(\mathrm{mg} \mathrm{g}^{-1}\right)$ & 217 & 244 & 270 & 294 \\
& $K_{L}\left(\mathrm{~L} \mathrm{mg}^{-1}\right)$ & 9.2 & 6.8 & 6.2 & 4.9 \\
\multirow{3}{*}{ Freundlich } & $\mathrm{R}^{2}$ & 0.9972 & 0.9975 & 0.9989 & 0.9984 \\
& $K_{F}$ & 190 & 201 & 223 & 239 \\
& $n$ & 3.5 & 3.2 & 3.9 & 2.9 \\
& $\mathrm{R}^{2}$ & 0.8203 & 0.8112 & 0.9371 & 0.9271 \\
\hline
\end{tabular}

Reusability and Regeneration

The reusability and regeneration of the $\beta$-cyclodextrin-decorated magnetic activated carbon composite were studied in order to investigate its practical application in water treatment processes. The regenerated and recycled results of the magnetic adsorbent (Figure 9) demonstrated that the adsorption/desorption (recovery) cycles for E1, E2, HYD and PRO solutions were not affected for up to eight runs of the regenerated magnetic adsorbent. This phenomenon suggested that the as-prepared adsorbent could be easily recovered and reused effectively. Therefore, $\beta$-cyclodextrin-decorated magnetic activated carbon composite has the potential for application in the determination of steroid hormones in water.

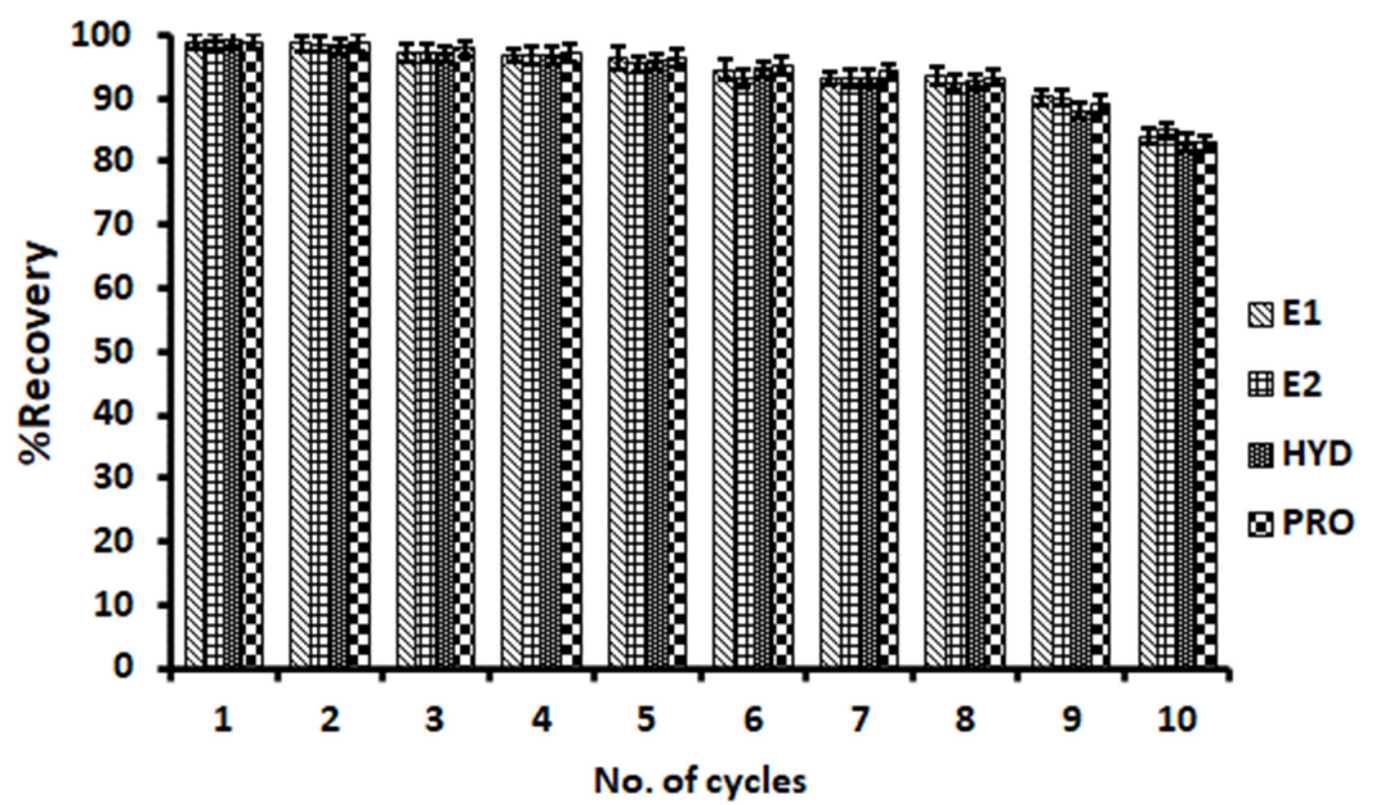

Figure 9. Regeneration of $\beta$-cyclodextrin-decorated magnetic activated carbon composite (initial concentration: $\left.\mathrm{C}_{0}=100 \mu \mathrm{g} \mathrm{L}^{-1}\right)(n=3)$.

\section{Conclusions}

Even though the use of some steroid hormones was banned due to their endocrine disruptor abilities, traces of these pollutants are still found in different water matrices. As such, analytical methods able to determine these compounds from complex matrices are of urgent necessity. In this work, a simple and effective magnetic solid-phase microextraction procedure was developed, which showed comparable analytical performance to other solidphase extraction-based methods found in the previous literature. The adsorption of steroid hormones onto the adsorbent was found to be described by the Langmuir adsorption isotherm, with high maximum adsorption capacities of 217, 244, 270 and $294 \mathrm{mg} \mathrm{g}^{-1}$ for E1, E2, HYD and PRO. Moreover, the adsorbent could be used up to eight times while maintaining a $92 \%$ recovery. 
Supplementary Materials: The following are available online, Table S1: Structural and physical properties of target analytes, Figure S1: Three-dimensional response surface plot showing the result (E2 (A-C), HYD (D-F) and PRO (G-I)) of the interaction of (A) eluent volume (EV) and mass of adsorbent (MA), (B) extraction time (ET) and MA and (C) EV and ET on \% R, Figure S2: Profiles for desirability for the extraction of E2, HYD and PRO, Figure S3: Typical chromatogram of steroid hormones showing peaks for 1: estrone, 2: $\beta$-estradiol, 3: hydrocortisone and 4: progesterone at $250 \mathrm{~nm}$. Flow rate of $1.00 \mathrm{~mL} \mathrm{~min}^{-1}$ and solvent mixture of $55 \%$ mobile phase A (water) and $45 \%$ mobile phase B (acetonitrile), using an isocratic elution system.

Author Contributions: Conceptualization, A.M., P.N.N. and B.M.; methodology, A.M. and A.N.; software, P.N.N.; validation, A.M.; formal analysis, A.M. and A.N.; investigation, A.M.; resources, P.N.N. and B.M.; data curation, A.M. and B.M.; writing-original draft preparation, A.M. and A.N.; writing-review and editing, P.N.N.; supervision, P.N.N. and B.M.; project administration, P.N.N. and B.M.; funding acquisition, P.N.N. and B.M. All authors have read and agreed to the published version of the manuscript.

Funding: This research was funded by the National Research Foundation innovation (NRF, South Africa, grant numbers 113010 (A.M.) and 91230 (A.N.)).

Acknowledgments: The authors are grateful to the Department of Chemical Sciences, University of Johannesburg (Doornfontein Campus), for equipment and for providing laboratory space to complete this project.

Conflicts of Interest: The authors declare no conflict of interest.

Sample Availability: Samples of the compounds are available from the authors.

\section{References}

1. Nezami, A.; Nosrati, R.; Golichenari, B.; Rezaee, R. Nanomaterial-based aptasensors and bioaf fi nity sensors for quantitative detection of 17 b-estradiol. Trends Anal. Chem. 2017, 94, 95-105. [CrossRef]

2. Puckowski, A.; Mioduszewska, K.; Łukaszewicz, P.; Borecka, M.; Caban, M.; Maszkowska, J.; Stepnowski, P. Bioaccumulation and analytics of pharmaceutical residues in the environment: A review. J. Pharm. Biomed. Anal. 2016, 127, 232-255. [CrossRef] [PubMed]

3. López-García, M.; Romero-González, R.; Frenich, A.G.; Frenich, A.G. Determination of steroid hormones and their metabolite in several types of meat samples by ultra high performance liquid chromatography-Orbitrap high resolution mass spectrometry. J. Chromatogr. A 2018, 1540, 21-30. [CrossRef]

4. di Donna, L.; Benabdelkamel, H.; Taverna, D.; Indelicato, S.; Aiello, D.; Napoli, A.; Sindona, G.; Mazzotti, F. Determination of ketosteroid hormones in meat by liquid chromatography tandem mass spectrometry and derivatization chemistry. Anal. Bioanal. Chem. 2015, 407, 5835-5842. [CrossRef] [PubMed]

5. Smajdor, J.; Piech, R.; Rumin, M.; Bator, B.P. New high sensitive hydrocortisone determination by means of adsorptive stripping voltammetry on renewable mercury film silver based electrode. Electrochim. Acta 2015, 182, 67-72. [CrossRef]

6. Merlo, F.; Speltini, A.; Maraschi, F.; Sturini, M.; Profumo, A. HPLC-MS/MS multiclass determination of steroid hormones in environmental waters after preconcentration on the carbonaceous sorbent HA-C@silica. Arab. J. Chem. 2020, 13, 4673-4680. [CrossRef]

7. Yang, Y.; Shao, B.; Zhang, J.; Wu, Y.; Duan, H. Determination of the residues of 50 anabolic hormones in muscle, milk and liver by very-high-pressure liquid chromatography-electrospray ionization tandem mass spectrometry. J. Chromatogr. B 2009, 877, 489-496. [CrossRef]

8. Qin, H.; Li, B.; Liu, M.S.; Yang, Y.L. Separation and pre-concentration of glucocorticoids in water samples by ionic liquid supported vortex-assisted synergic microextraction and HPLC determination. J. Sep. Sci. 2013, 36, 1463-1469. [CrossRef]

9. Manickum, T.; John, W. The current preference for the immuno-analytical ELISA method for quantitation of steroid hormones (endocrine disruptor compounds) in wastewater in South Africa. Anal. Bioanal. Chem. 2015, 407, 4949-4970. [CrossRef] [PubMed]

10. Avar, P.; Maász, G.; Takács, P.; Lovas, S.; Zrínyi, Z.; Svigruha, R.; Takátsy, A.; Tóth, L.G.; Pirger, Z. HPLC-MS/MS analysis of steroid hormones in environmental water samples. Drug Test. Anal. 2016, 8, 123-127. [CrossRef]

11. Fonseca, A.P.; Lima, D.L.D.; Esteves, V.I. Degradation by solar radiation of estrogenic hormones monitored by UV-visible spectroscopy and capillary electrophoresis. Water Air Soil Pollut. 2011, 215, 441-447. [CrossRef]

12. Huysman, S.; van Meulebroek, L.; Vanryckeghem, F.; van Langenhove, H.; Demeestere, K.; Vanhaecke, L. Development and validation of an ultra-high performance liquid chromatographic high resolution Q-Orbitrap mass spectrometric method for the simultaneous determination of steroidal endocrine disrupting compounds in aquatic matrices. Anal. Chim. Acta 2017, 984, 140-150. [CrossRef] [PubMed] 
13. Wang, Q.; Zhang, A.; Pan, X.; Chen, L. Simultaneous determination of sex hormones in egg products by $\mathrm{ZnCl}_{2}$ depositing lipid, solid-phase extraction and ultra performance liquid chromatography/electrospray ionization tandem mass spectrometry. Anal. Chim. Acta 2010, 678, 108-116. [CrossRef]

14. Attalah, E.; Nasr, Y.S.; El-gammal, H.A.; El-dien, F.A.N.; Attalah, E.; Nasr, Y.S.; El-gammal, H.A.; El-dien, F.A.N. Food Additives \& Contaminants: Part A Optimisation and validation of a new analytical method for the determination of four natural and synthetic hormones using LC-ESI-MS/MS. Food Addit. Contam. Part A 2016, 33, 1545-1556.

15. Fan, Y.B.; Yin, Y.M.; Jiang, W.B.; Chen, Y.P.; Yang, J.W.; Wu, J.; Xie, M.X. Simultaneous determination of ten steroid hormones in animal origin food by matrix solid-phase dispersion and liquid chromatography-electrospray tandem mass spectrometry. Food Chem. 2014, 142, 170-177. [CrossRef]

16. Aufartová, J.; Mahugo-santana, C.; Sosa-ferrera, Z.; Santana-rodríguez, J.J.; Nováková, L.; Solich, P. Determination of steroid hormones in biological and environmental samples using green microextraction techniques: An overview. Anal. Chim. Acta 2011, 704, 33-46. [CrossRef]

17. Lu, C.; Wang, M.; Mu, J.; Han, D.; Bai, Y.; Zhang, H. Simultaneous determination of eighteen steroid hormones in antler velvet by gas chromatography-tandem mass spectrometry. Food Chem. 2013, 141, 1796-1806. [CrossRef]

18. Ahmadi, M.; Elmongy, H.; Madrakian, T. Analytica Chimica Acta Nanomaterials as sorbents for sample preparation in bioanalysis: A review. Anal. Chim. Acta 2017, 958, 1-21. [CrossRef] [PubMed]

19. Socas-rodríguez, B.; Asensio-ramos, M.; Hernández-borges, J.; Rodríguez-delgado, Á. Hollow-fiber liquid-phase microextraction for the determination of natural and synthetic estrogens in milk samples. J. Chromatogr. A 2013, 1313, 175-184. [CrossRef]

20. Dimpe, K.M.; Nomngongo, P.N. Current sample preparation methodologies for analysis of emerging pollutants in different environmental matrices. TrAC Trends Anal. Chem. 2016, 82, 199-207. [CrossRef]

21. Żwir-Ferenc, A.; Biziuk, M. Solid Phase Extraction Technique-Trends, Opportunities and Applications. Polish J. Environ. Stud. 2006, 15, 677-690.

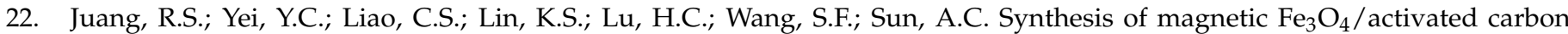
nanocomposites with high surface area as recoverable adsorbents. J. Taiwan Inst. Chem. Eng. 2018, 90, 51-60. [CrossRef]

23. Liu, W.; Zhang, J.; Zhang, C.; Ren, L. Preparation and evaluation of activated carbon-based iron-containing adsorbents for enhanced Cr(VI) removal: Mechanism study. Chem. Eng. J. 2012, 189-190, 295-302. [CrossRef]

24. Cui, H.; Turn, S.Q. Adsorption/desorption of dimethylsulfide on activated carbon modified with iron chloride. Appl. Catal. B Environ. 2009, 88, 25-31. [CrossRef]

25. Wang, H.; Zhou, Y.; Guo, Y.; Liu, W.; Dong, C.; Wu, Y.; Li, S.; Shuang, S. $\beta$-Cyclodextrin/Fe ${ }_{3} \mathrm{O}_{4}$ hybrid magnetic nano-composite modified glassy carbon electrode for tryptophan sensing. Sens. Actuators B Chem. 2012, 163, 171-178. [CrossRef]

26. Liu, G.; Li, L.; Xu, D.; Huang, X.; Xu, X.; Zheng, S.; Zhang, Y.; Lin, H. Metal-organic framework preparation using magnetic graphene oxide- $\beta$-cyclodextrin for neonicotinoid pesticide adsorption and removal. Carbohydr. Polym. 2017, 175, 584-591. [CrossRef]

27. Zhang, F.; Wu, W.; Sharma, S.; Tong, G.; Deng, Y. Synthesis of Cyclodextrin-functionalized Cellulose Nanofibril Aerogel as a Highly Effective Adsorbent for Phenol Pollutant Removal. BioResources 2015, 10, 7555-7568. [CrossRef]

28. Li, J.; Qiu, C.; Fan, H.; Bai, Y.; Jin, Z.; Wang, J. A Novel Cyclodextrin-Functionalized Hybrid Silicon Wastewater Nano-Adsorbent Material and Its Adsorption Properties. Molecules 2018, 23, 1485. [CrossRef]

29. Kawano, S.; Kida, T.; Miyawaki, K.; Noguchi, Y.; Kato, E.; Nakano, T.; Akashi, M. Cyclodextrin polymers as highly effective adsorbents for removal and recovery of polychlorobiphenyl (PCB) contaminants in insulating oil. Environ. Sci. Technol. 2014, 48, 8094-8100. [CrossRef] [PubMed]

30. Yu, F.; Chen, D.; Ma, J. Synthesis of Cyclodextrin-based Adsorbents and its Application for Organic Pollutant Removal from Water. Curr. Org. Chem. 2017, 21, 1976-1990.

31. Feng, J.; Sun, M.; Bu, Y.; Luo, C. Development of a functionalized polymeric ionic liquid monolith for solid-phase microextraction of polar endocrine disrupting chemicals in aqueous samples coupled to high-performance liquid chromatography. Anal. Bioanal. Chem. 2015, 407, 7025-7035. [CrossRef]

32. Song, X.; Ha, W.; Chen, J.; Shi, Y. Application of $\beta$-cyclodextrin-modified, carbon nanotube-reinforced hollow fiber to solid-phase microextraction of plant hormones. J. Chromatogr. A 2014, 1374, 23-30. [CrossRef] [PubMed]

33. Dimpe, K.M.; Mpupa, A.; Nomngongo, P.N. Microwave assisted solid phase extraction for separation preconcentration sulfamethoxazole in wastewater using tyre based activated carbon as solid phase material prior to spectrophotometric determination. Spectrochim. Acta-Part A Mol. Biomol. Spectrosc. 2018, 188, 341-348. [CrossRef]

34. Mashile, P.P.; Mpupa, A.; Nomngongo, P.N. Adsorptive removal of microcystin-LR from surface and waste water using tyrebasedbpowdered activated carbon: Kinetics and isotherms. Toxicon 2018, 145, 23-31. [CrossRef]

35. Nyaba, L.; Matong, J.M.; Nomngongo, P.N. Nanoparticles consisting of magnetite and $\mathrm{Al}_{2} \mathrm{O}_{3}$ for ligandless ultrasound-assisted dispersive solid phase microextraction of $\mathrm{Sb}$, Mo and V prior to their determination by ICP-OES. Microchim. Acta 2016, 183, 1289-1297. [CrossRef]

36. Hoga, C.A.; Reche, K.V.G.; Almeida, F.L.; Reis, V.R.; Cordeiro, R.P.; Anadón, A.; Reyes, F.G.R. Development and validation of an analytical method for the determination of $17 \beta$-estradiol residues in muscle of tambaqui (Colossoma macropomum Cuvier, 1818) by LC-MS/MS and its application in samples from a fish sexual reversion study. J. Chromatogr. B 2019, 1128, 121774. [CrossRef] 
37. Oliveira, L.C.A.; Rios, R.V.R.A.; Fabris, J.D.; Garg, V.; Sapag, K.; Lago, R.M. Activated carbon/iron oxide magnetic composites for the adsorption of contaminants in water. Carbon 2003, 40, 2177-2183. [CrossRef]

38. Filippou, O.; Deliyanni, E.A.; Samanidou, V.F. Fabrication and evaluation of magnetic activated carbon as adsorbent for ultrasonic assisted magnetic solid phase dispersive extraction of bisphenol A from milk prior to high performance liquid chromatographic analysis with ultraviolet detection. J. Chromatogr. A 2017, 1479, 20-31. [CrossRef] [PubMed]

39. Li, N.; Chen, J.; Shi, Y.-P. Magnetic reduced graphene oxide functionalized with $\beta$-cyclodextrin as magnetic solid-phase extraction adsorbents for the determination of phytohormones in tomatoes coupled with high performance liquid chromatography. J. Chromatogr. A 2016, 1441, 24-33. [CrossRef]

40. Martendal, E.; Budziak, D.; Carasek, E. Application of fractional factorial experimental and Box-Behnken designs for optimization of single-drop microextraction of 2,4,6-trichloroanisole and 2,4,6-tribromoanisole from wine samples. J. Chromatogr. A 2007, 1148, 131-136. [CrossRef] [PubMed]

41. Wilnkison, L. Revising the Pareto chart. Am. Stat. 2006, 60, 332-334.

42. Mpupa, A.; Mashile, G.P.; Nomngongo, P.N. Vortex assisted-supramolecular solvent based microextraction coupled with spectrophotometric determination of triclosan in environmental water samples. Open Chem. 2017, 15, 255-262. [CrossRef]

43. Ragavan, K.V.; Rastogi, N.K. $\beta$-Cyclodextrin capped graphene-magnetite nanocomposite for selective adsorption of Bisphenol-A. Carbohydr. Polym. 2017, 168, 129-137. [CrossRef]

44. Jiang, L.; Liu, Y.; Liu, S.; Hu, X.; Zeng, G.; Hu, X.; Liu, S.; Liu, S.; Huang, B.; Li, M. Fabrication of $\beta$-cyclodextrin/poly (l-glutamic acid) supported magnetic graphene oxide and its adsorption behavior for 17ß-estradiol. Chem. Eng. J. 2017, 308, 597-605. [CrossRef]

45. Mashile, G.P.; Mpupa, A.; Nomngongo, P.N. In-Syringe Micro Solid-Phase Extraction Method for the Separation and Preconcentration of Parabens in environmental water. Molecules 2018, 23, 1450-1465. [CrossRef] [PubMed]

46. Liao, K.; Mei, M.; Li, H.; Huang, X. Multiple monolithic fiber solid-phase microextraction based on a polymeric ionic liquid with high-performance liquid chromatography for the determination of steroid sex hormones in water and urine. J. Sep. Sci. 2016, 39, 566-575. [CrossRef]

47. Sampaio, N.M.F.M.; Castilhos, N.D.B.; da Silva, B.C.; Riegel-Vidotti, I.C.; Silva, B.J.G. Evaluation of Polyvinyl Alcohol/PectinBased Hydrogel Disks as Extraction Phase for Determination of Steroidal Hormones in Aqueous Samples by GC-MS/MS Molecules 2019, 24, 40. [CrossRef] [PubMed]

48. Jaukovi, Z.D.; Gruji, S.D.; Mati, I.V.; Lau, M.D. Determination of sterols and steroid hormones in surface water and wastewater using liquid chromatography-atmospheric pressure chemical ionization-mass spectrometry. Anal. Chim. Acta 2017, 135, 39-47. [CrossRef]

49. Pessoa, G.P.; de Souza, N.C.; Vidal, C.B.; Alves, J.A.C.; Firmino, P.I.M.; Nascimento, R.F.; Santos, A.B.d. Occurrence and removal of estrogens in Brazilian wastewater treatment plants. Sci. Total Environ. 2014, 490, 288-295. [CrossRef]

50. Atkinson, S.K.; Marlatt, V.L.; Kimpe, L.E.; Lean, D.R.S.; Trudeau, V.L.; Blais, J.M. The occurrence of steroidal estrogens in south-eastern Ontario wastewater treatment plants. Sci. Total Environ. 2012, 430, 119-125. [CrossRef] [PubMed]

51. Manzo, V.; Goya-Pacheco, J.; Arismendi, D.; Becerra-Herrera, M.; Castillo-Aguirre, A.; Castillo-Felices, R.; Rosero-Moreano, M.; Carasek, E.; Richter, P. Cork sheet as a sorptive phase to extract hormones from water by rotating-disk sorptive extraction (RDSE). Anal. Chim. Acta 2019, 1087, 1-10. [CrossRef] [PubMed]

52. Shishov, A.; Sviridov, I.; Timofeeva, I.; Chibisova, N.; Moskvin, L.; Bulatov, A. An effervescence tablet-assisted switchable solventbased microextraction: On-site preconcentration of steroid hormones in water samples followed by HPLC-UV determination. J. Mol. Liq. 2017, 247, 246-253. [CrossRef]

53. Mhuka, V.; Dube, S.; Nindi, M.M. Occurrence of pharmaceutical and personal care products (PPCPs) in wastewater and receiving waters in South Africa using LC-Orbitrap ${ }^{\mathrm{TM}}$ MS. Emerg. Contam. 2020, 6, 250-258. [CrossRef]

54. Langmuir, I. The evaporation, condensation and reflection of molecules and the mechanism of adsorption. Phys. Rev. 1916, 8 , 149-156. [CrossRef]

55. Freundlich, H. Über die adsorption in lösungen. Z. Für Phys. Chem. 1907, 57, 385-470. [CrossRef]

56. Nqombolo, A.; Mpupa, A.; Gugushe, A.S.; Moutloali, R.M.; Nomngongo, P.N. Adsorptive removal of lead from acid mine drainage using cobalt-methylimidazolate framework as an adsorbent: Kinetics, isotherm, and regeneration. Environ. Sci. Pollut. Res. 2019, 26, 3330-3339. [CrossRef] [PubMed] 